\title{
Common Mechanisms of Drug Interactions with Sodium and T-Type Calcium Channels
}

\author{
Chris Bladen and Gerald W. Zamponi
}

Department of Physiology and Pharmacology, Hotchkiss Brain Institute, University of Calgary, Calgary, Alberta, Canada

Received April 30, 2012; accepted June 6, 2012

\begin{abstract}
Voltage-gated sodium $\left(\mathrm{Na}_{v}\right)$ and calcium $\left(\mathrm{Ca}_{v}\right)$ channels play important roles in physiological processes, including neuronal and cardiac pacemaker activity, vascular smooth muscle contraction, and nociception. They are thought to share a common ancestry, and, in particular, T-type calcium (T-type) channels share structural similarities with $\mathrm{Na}_{v}$ channels, both with regard to membrane topology and with regard to gating kinetics, including rapid inactivation. We thus reasoned that certain drugs acting on $\mathrm{Na}_{v}$ channels may also modulate the activities of T-type channels. Here we show that the specific $\mathrm{Na}_{v} 1.8$ blocker 5-(4-chlorophenyl- $N$-(3,5-dimethoxyphenyl)furan-2-carboxamide (A803467) tonically blocks T-type channels in the low micromolar range. Similarly to $\mathrm{Na}_{\mathrm{v}} 1.8$, this compound causes a
\end{abstract}

significant hyperpolarizing shift in the voltage dependence of inactivation and seems to promote a slow inactivation-like phenotype. We further hypothesized that the structural similarity between T-type and $\mathrm{Na}_{v}$ channels may extend to structurally similar drug-binding sites. Sequence alignment revealed several highly conserved regions between T-type and $\mathrm{Na}_{v}$ channels that corresponded to drug-binding sites known to alter voltage-dependent gating kinetics. Mutation of amino acid residues in this regions within human $\mathrm{Ca}_{\mathrm{v}} 3.2$ T-type channels altered A803467 blocking affinity severalfold, suggesting that these sites may be exploited for the design of mixed T-type and $\mathrm{Na}_{\mathrm{v}}$ channel blockers that could potentially act synergistically to normalize aberrant neuronal activity.

\section{Introduction}

$\mathrm{Na}_{\mathrm{v}}$ channels mediate the induction and propagation of action potentials in most electrically excitable cells ( $\mathrm{Yu}$ and Catterall, 2004). The mammalian genome encodes nine different types of $\mathrm{Na}_{\mathrm{v}} \alpha$ subunits that are functionally classified as either tetrodotoxin (TTX)-sensitive or TTX-resistant, with the latter exhibiting slower inactivation kinetics than other $\mathrm{Na}_{\mathrm{v}}$ channel subtypes (Waxman et al., 1999; Blair and Bean, 2002). The various $\mathrm{Na}_{\mathrm{v}}$ channel $\alpha$ subunits share a common transmembrane topology of four homologous domains that each contain six membrane-spanning helices plus a p-loop. Whereas the $\alpha$ subunits define the $\mathrm{Na}_{\mathrm{v}}$ channel isoform and contain all of the machinery to form a sodium-selective voltage activated channel, their functional properties are modulated by association with ancillary $\beta 1$ and $\beta 2$ subunits (for review, see Isom, 2001). Mutations in various $\mathrm{Na}_{\mathrm{v}}$ channel subunits have been linked to disorders such as paramyotonia

This work was supported by the Canadian Institutes of Health Research (operating grants to G.W.Z.). G.W.Z. is a Canada Research Chair and an Alberta Innovates-Health Solutions Scientist. C.B. holds a T. Chen Fong studentship and an Alberta Innovates-Health Solutions studentship award.

Article, publication date, and citation information can be found at http://molpharm.aspetjournals.org.

http://dx.doi.org/10.1124/mol.112.079715. congenita, cardiac arrhythmias, epilepsy, and both hypersensitivity and insensitivity to pain, thus underscoring their importance for nerve, muscle, and heart function (Catterall et al., 2008; Jarecki et al., 2010).

Low-voltage-activated (LVA), i.e., T-type, channels, trigger low-threshold depolarizations that in turn lead to the initiation of action potentials (Cain and Snutch, 2010; Bender et al., 2012). These channels can be activated by small membrane depolarizations and display a small single-channel conductance, and compared with other $\mathrm{Ca}_{\mathrm{v}}$ channel subtypes, they display rapid activation and inactivation kinetics (Perez-Reyes, 2003). T-type channels are encoded by one of three different types of $\mathrm{Ca}_{\mathrm{v}} 3 \alpha 1$ subunits $\left(\mathrm{Ca}_{\mathrm{v}} 3.1, \mathrm{Ca}_{\mathrm{v}} 3.2\right.$, or $\mathrm{Ca}_{\mathrm{v}} 3.3$, whose membrane topology is similar to that of $\mathrm{Na}_{\mathrm{v}}$ channels (Catterall et al., 2005). Mutations in $\mathrm{Ca}_{\mathrm{v}} 3.2 \mathrm{~T}$-type channels have been linked to absence seizures (Khosravani and Zamponi, 2006; Heron et al., 2007). Moreover, up-regulation of $\mathrm{Ca}_{\mathrm{v}} 3.2 \mathrm{~T}$-type channel activity in primary afferent fibers has been linked to the development of chronic pain (for reviews, see Altier and Zamponi, 2004; Park and Luo, 2010), and T-type channel dysfunction contributes to cardiac hypertrophy (Cribbs, 2010; David et al., 2010). Both $\mathrm{Na}_{\mathrm{v}}$ channels and T-type channels contribute to neuronal excitability and to similar disorders such as epilepsy and pain. Indeed, knock-

ABBREVIATIONS: $\mathrm{Na}_{v}$, voltage-gated sodium channel; TTX, tetrodotoxin; LAV, low-voltage-activated; Ca ${ }_{v}$, voltage-gated calcium channel; A803467, 5-(4-chlorophenyl-N-(3,5-dimethoxyphenyl)furan-2-carboxamide; DMSO, dimethyl sulfoxide; $r$, rat; $h$, human. 
out of $\mathrm{Na}_{\mathrm{v}} 1.8$ and $\mathrm{Ca}_{\mathrm{v}} 3.2$ results in hyposensitivity to pain (for reviews, see Wang et al., 2011; Cregg et al., 2010), suggesting the possibility that mixed $\mathrm{Na}_{\mathrm{v}} / \mathrm{T}$-type channel blockers may be a possible strategy for the development of new analgesics (Hildebrand et al., 2010). 5-(4-Chlorophenyl- $N$ (3,5-dimethoxyphenyl)furan-2-carboxamide (A803467), a new inhibitor of $\mathrm{Na}_{\mathrm{v}} 1.8$ channels, has been shown to be efficacious in animal pain models (McGaraughty et al., 2008). The interaction site of $\mathrm{A} 803467$ on the $\mathrm{Na}_{\mathrm{v}}$ channel complex is unknown, but its mode of action seems to be preferential binding to the slow inactivated state of this channel (Jarvis et al., 2007).

Here we show that A803467 inhibits T-type channels in the low micromolar range and mediates a hyperpolarizing shift in the voltage dependence of activation and inactivation. In addition, the compound promotes a slow inactivation-like phenotype. Sequence alignment between T-type and $\mathrm{Na}_{\mathrm{v}}$ channels and their local anesthetic interaction site identified key residues involved in the blocking action of this compound on T-type channels.

\section{Materials and Methods}

cDNA Constructs. Human $\mathrm{Ca}_{\mathrm{v}} 3.2$, rat $\mathrm{Ca}_{\mathrm{v}} 1.2$, and rat $\mathrm{Ca}_{\mathrm{v}} 2.1$ cDNA constructs, as well as ancillary $\mathrm{Ca}_{\mathrm{v}}$ channel subunit cDNAs were kindly provided by Dr. Terrance Snutch (University of British Columbia, Vancouver, BC, Canada). Human $\mathrm{Ca}_{\mathrm{v}} 3.3$ was obtained from Dr. Arnaud Monteil (Centre National de la Recherche Scientifique, Montpellier, France), and human $\mathrm{Ca}_{\mathrm{v}} 3.1$ was described previously by our laboratory (Beedle et al., 2002).

Site-Directed Mutagenesis. Site-directed mutagenesis was performed using the QuikChange II Site-Directed Mutagenesis Kit and protocols from Agilent Technologies, Inc. (Santa Clara, CA). Mutations were then verified by on-site sequencing of the full-length cDNA clone.

Chemicals. Unless stated otherwise, chemicals were purchased from Sigma-Aldrich (St. Louis, MO). A803467 was purchased from Tocris Bioscience (Ellisville, MO) and was dissolved in dimethyl sulfoxide (DMSO) at the stock concentration of 10 or $30 \mathrm{mM}$. Dilutions were made in external recording solutions so that the final concentration of DMSO was $0.1 \%$ or less. $\mathrm{Ca}_{\mathrm{v}}$ channel currents were not affected by $0.1 \%$ DMSO.

tsA-201 Cell Culture and Transfection. Human embryonic kidney tsA-201 cells were cultured and transfected using the calcium phosphate method as described previously (Altier et al., 2006). Enhanced green fluorescent protein DNA $(0.5 \mu \mathrm{g}$ of enhanced green fluorescent protein; Clontech, Mountain View, CA) was transfected as a marker. For experiments involving L- and P/Q-type channels, $\mathrm{rCa}_{\mathrm{v}} 1.2$ or $\mathrm{rCa}_{\mathrm{v}} 2.1, \alpha 1$ subunits $(3 \mu \mathrm{g})$, were each cotransfected with rat $\beta 1 \mathrm{~b}(3 \mu \mathrm{g})$ or rat $\beta 4(3 \mu \mathrm{g})$. For experiments involving T-type channels, $\mathrm{hCa}_{\mathrm{v}} 3.1, \mathrm{hCa}_{\mathrm{v}} 3.2$, and $\mathrm{hCa}_{\mathrm{v}} 3.3, \alpha 1$ subunits were transfected alone $(6 \mu \mathrm{g})$. Cells were resuspended with $0.25 \%(\mathrm{w} / \mathrm{v})$ trypsinEDTA (Invitrogen, Carlsbad, CA) and plated on glass coverslips a minimum of 3 to $4 \mathrm{~h}$ before patching and kept at $37^{\circ} \mathrm{C}$ and $5 \% \mathrm{CO}_{2}$.

Electrophysiology. Whole-cell voltage-clamp recordings on tsA201 cells were performed at room temperature 2 to 3 days after transfection. The external recording solution for calcium channel recordings contained $142 \mathrm{mM} \mathrm{CsCl}, 2 \mathrm{mM} \mathrm{CaCl}_{2}, 1 \mathrm{mM} \mathrm{MgCl} 2,10$ $\mathrm{mM}$ HEPES, and $10 \mathrm{mM}$ glucose, adjusted to $\mathrm{pH} 7.4$ with $\mathrm{CsOH}$. The external recording solution for $\mathrm{hCa}_{\mathrm{v}} 3.2 \mathrm{Q} 1848$ mutations and their $\mathrm{hCa}_{\mathrm{v}} 3.2$ wild-type controls contained $124 \mathrm{mM} \mathrm{CsCl}, 20 \mathrm{mM} \mathrm{BaCl}_{2}, 1$ $\mathrm{mM} \mathrm{MgCl} 2,10 \mathrm{mM}$ HEPES, and $10 \mathrm{mM}$ glucose, adjusted to $\mathrm{pH} 7.4$ with $\mathrm{CsOH}$. For all recordings, the internal patch pipette solution contained $126.5 \mathrm{mM} \mathrm{CsMeSO}$, $2 \mathrm{mM} \mathrm{MgCl}_{2}, 11 \mathrm{mM}$ EGTA, and 10 mM HEPES adjusted to $\mathrm{pH} 7.3$ with $\mathrm{CsOH}$. The internal solution was supplemented with $0.6 \mathrm{mM}$ GTP and $2 \mathrm{mM}$ ATP, which were added directly to the internal solution immediately before use. Liquid junction potentials for the above solutions were left uncorrected.

Drugs were prepared daily in external solution and were applied locally to cells with the use of a custom-built gravity-driven microperfusion system that allows solution exchanges in approximately $1 \mathrm{~s}$ (Feng et al., 2003). A series of vehicle-only control experiments was performed to ensure that there were no time-dependent shifts in half-activation and half-inactivation potentials, and no such changes were observed (data not shown). Currents were elicited from a holding potential of $-110 \mathrm{mV}$ and were measured by a conventional whole-cell patch clamp using an Axopatch 200B amplifier in combination with Clampex 9.2 software (Molecular Devices, Sunnyvale, CA). After establishment of the whole-cell configuration, cellular capacitance was minimized using the analog compensation available on the amplifier. Series resistance was $<10 \mathrm{M} \Omega$ and was compensated $>85 \%$ in all experiments. Data were filtered at $1 \mathrm{kHz}$ (8-pole Bessel) and digitized at $10 \mathrm{kHz}$ with a Digidata 1320 interface (Molecular Devices). In addition to collecting the raw data, a pulse/ number $\mathrm{p} / 4$ online leak-subtraction protocol was used (the $\mathrm{p} / 4$ protocol involved four very brief hyperpolarizing pulses, which should have a negligible effect on drug interactions). Non-leak-subtracted currents were acquired in parallel for quality control purposes. For current-voltage relation studies, the membrane potential was held at $-110 \mathrm{mV}$, and cells were depolarized from -90 to $20 \mathrm{mV}$ in $10-\mathrm{mV}$ increments. For steady-state inactivation studies, the membrane potential was depolarized by test pulses to $-30 \mathrm{mV}$ after $3.6-\mathrm{s}$ conditioning prepulses ranging from -110 to $-20 \mathrm{mV}$. Individual sweeps were separated by $10 \mathrm{~s}$ to allow for complete recovery from inactivation between conditioning pulses. The current amplitude obtained from each test pulse was then normalized to that observed at a holding potential of $-110 \mathrm{mV}$. For slow inactivation studies channels were assessed using a test pulse (P2) that followed a 10-s conditioning prepulse of between -70 and $-80 \mathrm{mV}$ to elicit a peak current amplitude that was approximately 50 to $60 \%$ of the initial test pulse (P1).

Data Analysis and Statistics. Data were analyzed using Clampfit 9.2 (Molecular Devices). Preparation of figures and curve fitting were performed with Origin 7.5 software (Origin Lab Corp., Northampton, MA). Current-voltage relationships were fitted with the modified Boltzmann equation: $I=\left[G_{\max } \cdot\left(V_{\mathrm{m}}-E_{\mathrm{rev}}\right)\right] /[1+$ $\left.\exp \left(V_{0.5 \text { act }}-V_{\mathrm{m}}\right) / k_{\mathrm{a}}\right]$, where $V_{\mathrm{m}}$ is the test potential, $V_{0.5}$ act is the half-activation potential, $E_{\text {rev }}$ is the reversal potential, $G_{\text {max }}$ is the maximum slope conductance, and $k_{\mathrm{a}}$ reflects the slope of the activation curve. Data from concentration dependence studies were fitted with the equation $y=A_{2}+\left(A_{1}-A_{2}\right) /\left[1+\left([C] / \mathrm{IC}_{50}\right)^{n}\right]$, where $A_{1}$ is initial current amplitude and $A_{2}$ is the current amplitude at saturating drug concentrations, $[C]$ is the drug concentration, and $n$ is the Hill coefficient. Statistical significance was determined by paired or unpaired Student's $t$ tests and one-way or repeated-measures analysis of variance followed by Tukey multiple comparison tests, and significant values were set as indicated in the text and figure legends. All data are given as means \pm S.E.s. Steady-state inactivation curves were fitted using the Boltzmann equation: $I=1 /(1+$ $\exp \left[\left(V_{\mathrm{m}}-V_{\mathrm{h}}\right) / S\right]$, where $V_{\mathrm{h}}$ is the half-inactivation potential and $S$ is the slope factor.

\section{Results}

A803467 Blocks T-Type Channels. A recent study identified a novel compound (A803467) as a specific and potent blocker of TTX-resistant $\mathrm{hNa}_{\mathrm{v}} 1.8$ channels (Jarvis et al., 2007). Given that T-type channels share structural similarities with $\mathrm{Na}_{\mathrm{v}}$ channels, we examined whether this compound may affect T-type channels at both therapeutic plasma and brain tissue concentrations (10-17 and $3-5 \mu \mathrm{M}$, respectively) (Jarvis et al., 2007). Figure 1, A and B, illustrates the effect of $5 \mu \mathrm{M}$ A803467 on human $\mathrm{Ca}_{\mathrm{v}} 3.2$ channels expressed tran- 
A

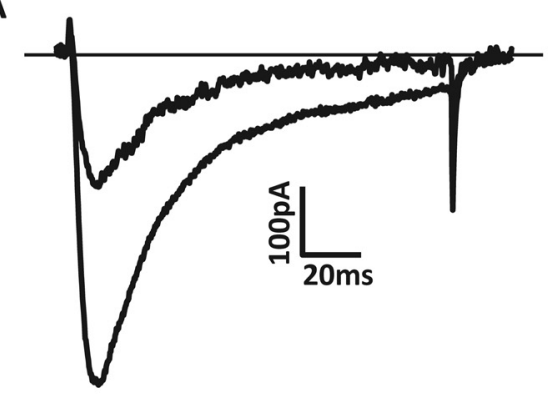

C

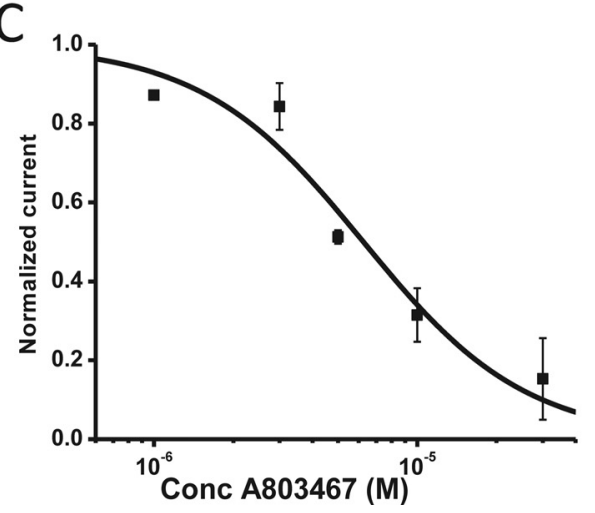

B

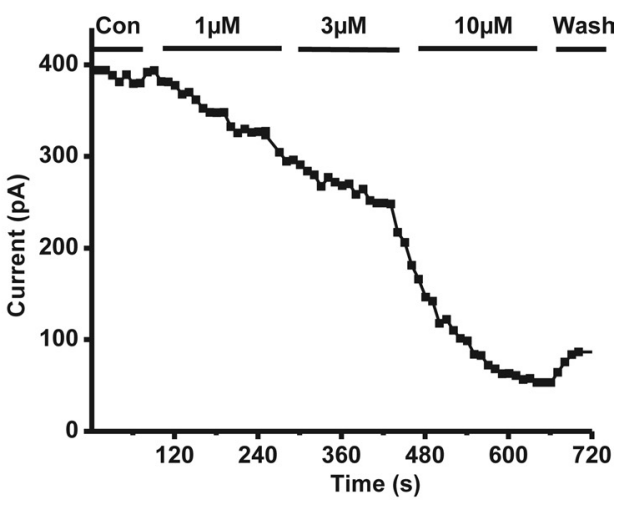

D

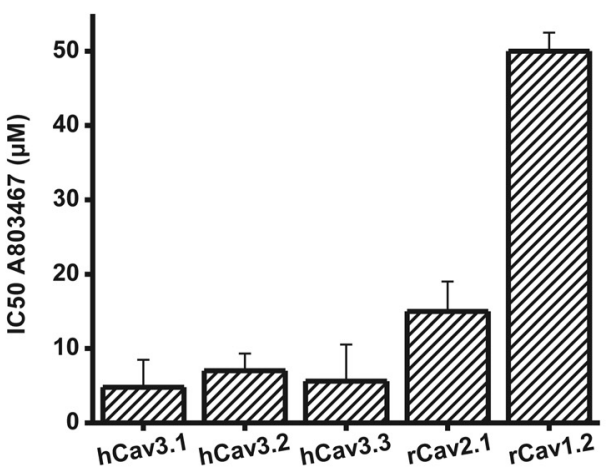

Fig. 1. Tonic block of voltage-gated calcium channels by A803467. A, representative current trace recorded from $\mathrm{Ca}_{3} 3.2$ channels transiently expressed in tsA-201 cells before and after application of $5 \mu \mathrm{M}$ A803467. Currents were elicited by stepping from a holding potential of $-110 \mathrm{mV}$ to a test potential of $-30 \mathrm{mV}$. B, representative time course of development of and recovery from A803467 block. C, ensemble dose-response curve for tonic $\mathrm{Ca}_{\mathrm{v}} 3.2$ channel inhibition by A803467. The solid line is a fit via the Hill equation. D, $\mathrm{IC}_{50}$ values for tonic $\mathrm{A} 803467$ block of rat high-voltage-activated and human LVA calcium channels. Data were obtained by fitting dose-response curves for each channel subtype $(n=6$ per channel). Error bars reflect S.E.s. Con, control. siently in tsA-201 cells at a holding potential of $-110 \mathrm{mV}$. As evident from the figure, this compound mediated robust peak current inhibition that could be partially reversed upon washout. The concentration dependence of this type of tonic (i.e., resting state) block could be well described by a Hill coefficient close to 1 (Fig. 1C), suggesting a bimolecular interaction between the channel and the blocker. We then examined the calcium channel subtype selectivity of A803467 (Fig. 1D) and found that all LVA subtypes were blocked with $\mathrm{IC}_{50}$ values in the low micromolar range, whereas two representative members of the high-voltage-activated channel family (i.e., L- and P/Q-type channels) exhibited lower affinities (i.e., higher $\mathrm{IC}_{50}$ values). A previous study has shown that this drug does not show significant block of N-type
A

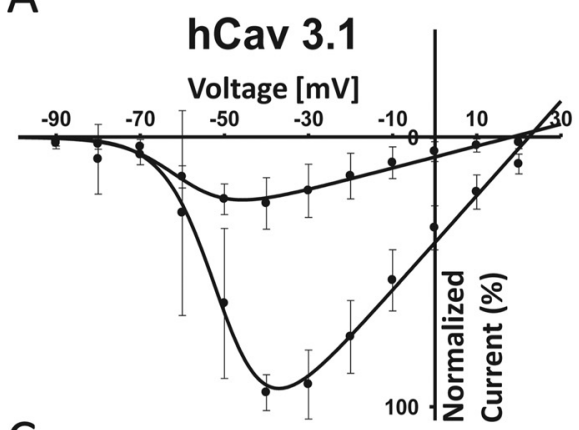

C

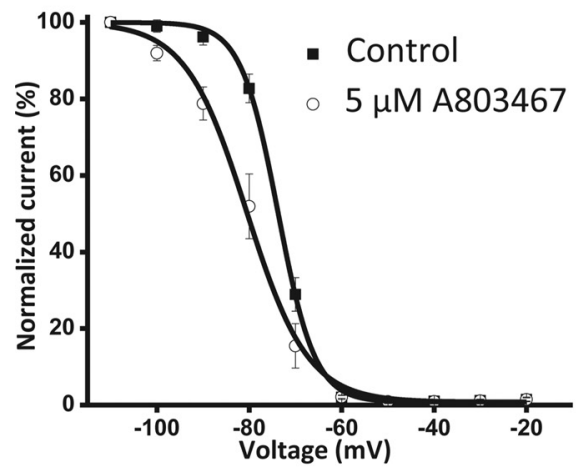

B

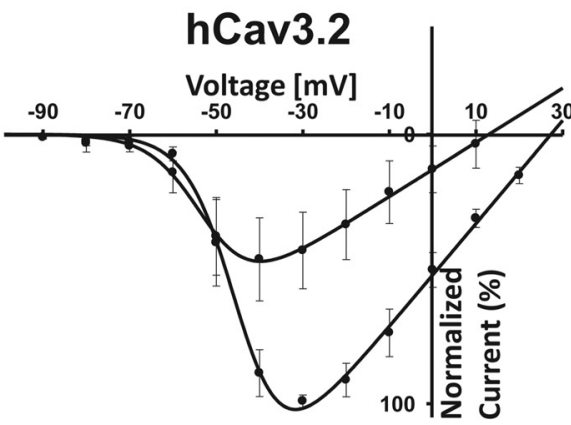

D

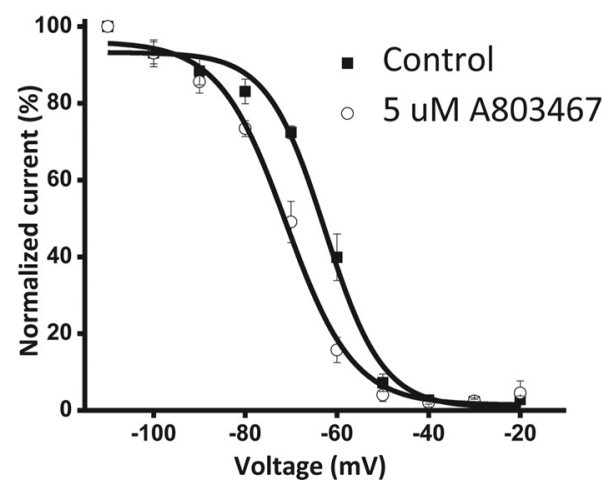

Fig. 2. A and B, current-voltage relations recorded before and after application of $5 \mu \mathrm{M}$ A803467 to $\mathrm{hCa} 3.1$ (A) or hCa 3.2 (B) channels. Data from multiple paired experiments are included in each figure. $\mathrm{C}$ and $\mathrm{D}$, steadystate inactivation curves for $\mathrm{hCa}_{\mathrm{v}} 3.1$ (C) and $\mathrm{hCa}_{\mathrm{v}} 3.2$ (D) channels in the absence (control) and presence of 5 $\mu \mathrm{M}$ A803467. Note the negative shift in the half-inactivation potential in the presence of A803467. The data were fitted with the Boltzmann equation; half-inactivation potentials obtained from the fits were as follows: $\mathrm{hCa}_{\mathrm{v}} 3.1$ : control $-74 \mathrm{mV}$, drug -84 $\mathrm{mV}$; and $\mathrm{hCa}_{\mathrm{v}} 3.2$ : control $-64 \mathrm{mV}$, drug $-71 \mathrm{mV}$. 
TABLE 1

Biophysical parameters of HVA and LVA calcium channels in the absence and the presence of A803467

\begin{tabular}{|c|c|c|c|c|c|}
\hline \multirow{2}{*}{ Calcium Channel } & \multicolumn{2}{|c|}{$V_{0.5 \text { act }}$} & \multicolumn{2}{|c|}{$V_{\mathrm{h}}$} & \multirow{2}{*}{ IC50 Tonic } \\
\hline & Control & Drug & Control & Drug & \\
\hline & \multicolumn{4}{|c|}{$m V$} & $\mu M$ \\
\hline $\mathrm{hCa}_{\mathrm{v}} 3.1$ & $-50.3 \pm 1.6(n=5)$ & $-60.0 \pm 1.6(n=5)^{*}$ & $-74 \pm 0.9(n=5)$ & $-84 \pm 1.8(n=5)^{*}$ & $4.8(n=6)$ \\
\hline $\mathrm{hCa}_{\mathrm{v}} 3.2$ & $-44.3 \pm 1.4(n=7)$ & $-52.1 \pm 1.2(n=7)^{*}$ & $-64.2 \pm 0.93(n=5)$ & $-71 \pm 0.45(n=5)^{* *}$ & $7.0 \pm 0.51(n=6)$ \\
\hline $\mathrm{hCa}_{\mathrm{v}} 3.3$ & $-47.8 \pm 1.6(n=6)$ & $-50.0 \pm 2.7(n=6)$, N.S. & $-79 \pm 1.7(n=9)$ & $-83 \pm 1.6(n=9)$, N.S. & $5.6(n=6)$ \\
\hline $\mathrm{rCa}_{\mathrm{v}} 2.1$ & $-15.8 \pm 1.3(n=5)$ & $-25 \pm 1.4(n=5)$ & N.A. & N.A. & $15.0(n=6)$ \\
\hline $\mathrm{rCa}_{\mathrm{v}} 1.2$ & N.A & N.A & N.A & N.A & $50.0(n=6)$ \\
\hline
\end{tabular}

N.A., not available; N.S., not significant.

$* P<0.05$, relative to control.

** $P<0.01$.

calcium channels, transient receptor potential vanilloid-1, KCNQ2/3 potassium channels, and other channels or receptors found in peripheral sensory neurons (Jarvis et al., 2007).

Unlike what has been reported for $\mathrm{hNa}_{\mathrm{v}} 1.8$ channels (Jarvis et al., 2007), we observed a significant hyperpolarizing shift in the half-activation voltages of both $\mathrm{Ca}_{\mathrm{v}} 3.1$ and $\mathrm{Ca}_{\mathrm{v}} 3.2$ channels (Fig. 2). There was also a trend toward more hyperpolarized voltages for $\mathrm{hCa}_{\mathrm{v}} 3.3$; however, these did not reach statistical significance (Table 1). Application of A803467 to T-type channels also resulted in a significant $(\sim 10 \mathrm{mV})$ hyperpolarizing shift in the half-inactivation potentials of $\mathrm{hCa}_{\mathrm{v}} 3.1$ and $\mathrm{hCa}_{\mathrm{v}} 3.2$ (Fig. 2, C and D) similar to that described previously for $\mathrm{hNa}_{\mathrm{v}} 1.8$ channels (Jarvis et al., 2007). The leftward shift in the steady-state inactivation curve is consistent with inactivated channel block (Hille, 1977).

Taken together, these data indicate that A803467 mediates both resting channel inhibition and inactivated channel block of T-type channels.

A803467 Block Promotes a Slow Inactivation-Like State of $\mathbf{h C a}_{\mathbf{v}}$ 3.2. Previous studies have identified slow inactivation channel blockers of $\mathrm{Na}_{\mathrm{v}} \mathrm{s}$ (Sheets et al., 2008), as well as mixed sodium/T-type channel blockers, which stabilize the slow inactivated conformation of these channels (Hildebrand et al., 2010). To determine whether A803467 may mediate a similar action on T-type channels, we used a slow inactivation protocol to induce a partial slow inactivated-like

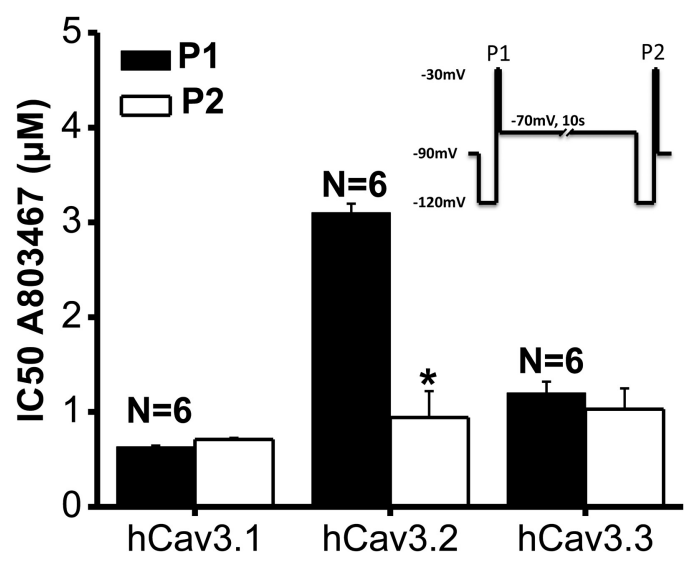

Fig. 3. Summary of $\mathrm{IC}_{50}$ values for $\mathrm{A} 803467$ block of $\mathrm{Ca}_{\mathrm{v}} 3$ channel subtypes in a partial slow inactivated state. The inset shows the wholecell voltage command protocol used to induce slow inactivation (i.e., a test pulse $\mathrm{P} 1$, followed by a 10 -s conditioning pulse to $-70 \mathrm{mV}$, a brief hyperpolarization to remove fast inactivation, and a second test pulse P2 to determine the fraction of slow inactivated channels). Note that only $\mathrm{Ca}_{\mathrm{v}} 3.2$ channels display a decrease in $\mathrm{IC}_{50}$ for A803467 inhibition during $\mathrm{P} 2$, indicating a selective increase of A803467 affinity for slow inactivated $\mathrm{Ca}_{\mathrm{v}}$.3.2 channels $(*, p<0.05$; Student's $t$ test). state of the channel. Specifically, we applied a brief test depolarization (P1) before a 10-s conditioning pulse to -70 $\mathrm{mV}$, which is expected to induce both fast and slow inactivation. This was followed by a brief hyperpolarizing step to induce recovery from fast inactivation of non-drug-bound channels. A second depolarizing test pulse (P2) allowed us to determine the fraction of channels in the slow inactivatedlike state (under our experimental conditions; this amounted to approximately $30 \%$ slow inactivation in the absence of the drug). The dose-dependent effects of A803467 on the currents elicited by P1 and P2 were then compared in order to ascertain the amount of resting versus slow inactivated-like channel block. As shown in Fig. 3, in hCa 3.2 channels, A803467 induced channel inhibition that resembled features of enhanced slow inactivation, as evident from a reduction in the $\mathrm{IC}_{50}$ of $\mathrm{P} 2$ current inhibition. In contrast, the $\mathrm{hCa}_{\mathrm{v}} 3.1$ and $\mathrm{hCa}_{\mathrm{v}} 3.3$ channels did not show stabilization of the slow inactivated-like channel conformation. The combined effects of A8023467 on different kinetic states of $\mathrm{hCa}_{\mathrm{v}} 3.2$ channels predict substantial total/combined inhibition of $\mathrm{Ca}_{\mathrm{v}} 3.2$ currents in the high nanomolar to the low micromolar range that is well within the therapeutic range of A803467.

A Locus Analogous to the $\mathrm{Na}_{\mathrm{v}}$ Local Anesthetic Binding Site Controls A803467 Block of $\mathrm{Ca}_{\mathbf{v}}$ 3.2. Given the structural similarity between T-type and $\mathrm{Na}_{\mathrm{v}}$ channels, we

\begin{tabular}{|c|c|}
\hline Nav1. 8 & YMIFFVLVIIFLGSFYLVNLILAVVT 397 \\
\hline Nav1.2 & YMIFFVLVIIFLGSFYLINLILAVVA 425 \\
\hline \multirow[t]{3}{*}{ Cav3.2 } & NFIYFILLIIVGSFFMINLCLVVIA 419 \\
\hline & 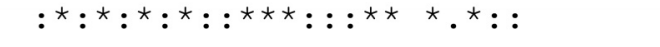 \\
\hline & 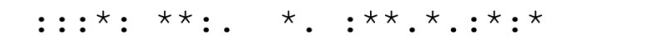 \\
\hline NavAb & AWVFFIPFIFVVTFVMINLV \\
\hline Nav1. 8 & MYLYFVIFIIFGGFFTLNLF $\underline{\mathbf{V} G V I I D N F} 14$ \\
\hline $\operatorname{Nav} 1.2$ & MYLYFVIFIIFGSFFTLNLFIGVIIDNF 1 \\
\hline \multirow[t]{2}{*}{ Cav3.2 } & MLLYFISFLLIVSFFVLNMF $\underline{\mathbf{V} G V V V E N F} 1$ \\
\hline & 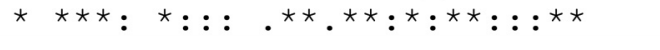 \\
\hline $\mathrm{Nav} 1.8$ & PAVGIIFFTTYIIISFLIMVNMY IAV 1720 \\
\hline $\mathrm{Nav} 1.2$ & PSVGIFFFVSYIIISFLVVVNMYYIAV 1774 \\
\hline $\operatorname{av} 3.2$ & PALSPVYFVTFVLVAQFVLVNV్VAV 185 \\
\hline & ${ }^{\star}::: \quad .:{ }^{\star} .::::::::::{ }^{\star}::{ }^{*}$ \\
\hline
\end{tabular}

Fig. 4. Sequence alignment of the local anesthetic binding regions in $\mathrm{Na}_{\mathrm{v}}$ channels with the analogous regions in $\mathrm{hCa}_{\mathrm{v}} 3.2$. Residues involved in local anesthetic binding to $\mathrm{Na}_{\mathrm{v}}$ channels are indicated in bold. Note the overall degree of sequence similarity between T-type channels, sodium channels, and the $\mathrm{Na}_{\mathrm{v}} \mathrm{Ab}$ bacterial sodium channel whose crystal structure has recently been resolved. 


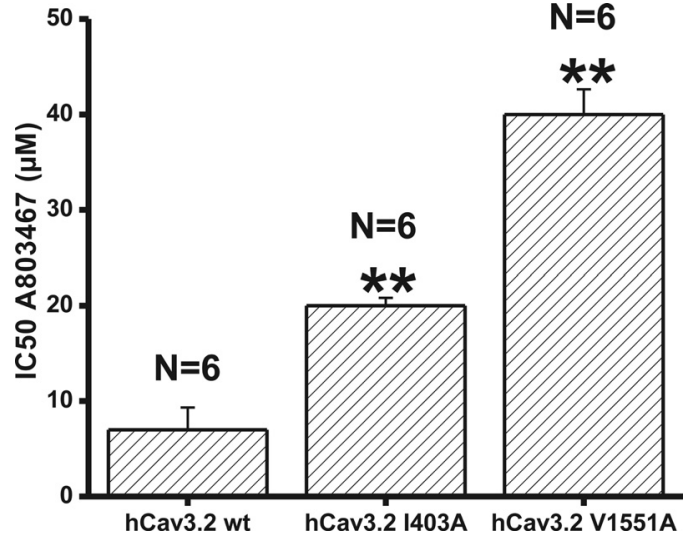

Fig. 5. Summary of $\mathrm{IC}_{50}$ values for tonic A803467 block of wild-type (wt) and mutant $\mathrm{Ca}_{\mathrm{v}} 3.2$ channels. Currents were elicited by stepping to a test potential of $-30 \mathrm{mV}$ from a holding potential of $-110 \mathrm{mV}$. Significance was assessed using analysis of variance $(* *, p<0.01)$.

hypothesized that the drug-binding site on these two types of channels may be conserved. Sodium channels possess multiple drug interaction sites, including a receptor site for binding of local anesthetics and anticonvulsive drugs (Lipkind and Fozzard, 2005). A key locus for local anesthetic block of $\mathrm{Na}_{\mathrm{v}}$ channels was first identified by Ragsdale et al. (1994). The authors revealed that Tyr1771 and Phe1764 in $\mathrm{Na}_{\mathrm{v}} 1.2$ were important determinants of local anesthetic block of $\mathrm{Na}_{\mathrm{v}} 1.2$ channels and that mutagenesis of these two residues (in particular residue 1764) resulted in a reduction in etidocaine blocking affinity for the channel. In $\mathrm{hCa}_{\mathrm{v}} 3.2$ channels, the residues equivalent to these two residues are valine and glutamine (Fig. 4), indicating that one key component of the local anesthetic-binding site is absent in T-type channels. However, Yarov-Yarovoy et al. $(2001,2002)$ identified several amino acid residues in the IS6 and IIIS6 segments of the $\mathrm{Na}_{\mathrm{v}}$ $1.2 \alpha$ subunit that also affected drug interactions. These authors showed that in addition to residues Tyr1771 and Phe1764, mutagenesis of Ile409 and Ile1469 reduced local anesthetic interactions. ClustalW2 multiple sequence alignment of $\mathrm{hNa}_{\mathrm{v}} 1.8$ versus $\mathrm{hNa}_{\mathrm{v}} 1.2$ and $\mathrm{hCa}_{\mathrm{v}} 3.2$ revealed that these regions were highly conserved in these channels (Fig. 4). The corresponding loci of these residues in $\mathrm{Ca}_{\mathrm{v}} 3.2$ are Ile403 and Val1551, indicating that $\mathrm{Ca}_{\mathrm{v}} 3.2$ channels may possess some of the structures needed for local anesthetic interactions.

To determine whether these residues may be involved in A803467 interactions with $\mathrm{hCa}_{\mathrm{v}} 3.2$, we replaced Ile403 and Val1551 with alanines and then assessed A803467 block of these mutant channels. As shown in Fig. 5, these amino acid substitutions resulted in a significant decrease in A803467 blocking affinity for $\mathrm{hCa}_{\mathrm{v}} 3.2$ (by more than 1 order of mag- nitude for the IIIS6 substitution). This effect was not secondarily due to reduced slow inactivation, because the only gating parameter that was significantly altered was a shift in half-activation voltage of the I403A mutant (Table 2).

Next, we tested whether these mutations affected the ability of A803467 to enhance slow inactivation of $\mathrm{hCa}_{\mathrm{v}} 3.2$. As shown in Fig. 6, the A803467-induced stabilization of a slow inactivated-like state of the wild-type channel was abolished in the two mutant channels.

To further support the hypothesis that a locus analogous to the sodium local anesthetic-binding site controls A803467 block of $\mathrm{Ca}_{\mathrm{v}} 3.2$, we introduced a tyrosine residue in position V1855 of $\mathrm{Ca}_{\mathrm{v}} 3.2$ (corresponding to Tyr1771 in $\mathrm{hNa}_{\mathrm{v}} 1.2$ ) and determined the consequences on the A803467 block of $\mathrm{hCa}_{\mathrm{v}} 3.2$ (Fig. 7). The introduction of Tyr1855 significantly increased A803467 resting state blocking affinity by approximately 4-fold (Fig. 7A) and preserved the ability of the compound to stabilize the fast inactivated state (Fig. 7B). Furthermore, we observed a significant increase in blocking activity in response to the slow inactivation pulse paradigm, as evident from a reduction in the $\mathrm{IC}_{50}$ during P2 (Fig. 7C). Unlike substitutions in positions 403 and 1551, tyrosine substitution of residue 1855 induced a $\sim 10 \mathrm{mV}$ depolarizing shift in the voltage dependences of activation (not shown) and inactivation (Fig. 7B), indicating that this locus is important for channel gating.

Finally, we mutated the glutamine residue in position 1848 of $\mathrm{hCa}_{\mathrm{v}} 3.2$ to the phenylalanine found in the corresponding position in $\mathrm{Na}_{\mathrm{v}} 1.2$ channels (Ragsdale et al., 1994) (Fig. 4). In addition, we also substituted this residue with another hydrophobic residue, leucine. When expressed in tsA-201 cells, both mutants yielded T-type currents, albeit with much reduced whole-cell current amplitudes compared with those seen with wild-type channels. In fact, reliable current recordings required us to increase the ionic strength of the extracellular recording solution to $20 \mathrm{mM}$ barium. Under these conditions, we were at least able to test the ability of A803467 to mediate tonic (resting) blocking affinity. As shown in Fig. 8, the compound exhibited a 20 -fold increase in affinity for the phenylalanine mutant and a 10-fold increase for the leucine mutant compared with wild-type channels bathed in the same barium solution. In both mutants, block was completely reversible upon washout (not shown).

Taken together, these data indicate that both tonic and slow inactivated-like channel block of $\mathrm{Ca}_{\mathrm{v}} 3.2$ channels by A803467 is mediated by interactions of this compound with residues that are analogous to those comprising the local anesthetic receptor site in $\mathrm{Na}_{\mathrm{v}}$ channels.

TABLE 2

Biophysical parameters of wild type and mutant $\mathrm{hCa}_{\mathrm{v}} 3.2$ calcium channels

\begin{tabular}{|c|c|c|c|c|c|}
\hline Calcium Channel & $V_{0.5 \text { act }}$ & $E_{\text {rev }}$ & $G_{\max }$ & $V_{\mathrm{h}}$ & $\mathrm{IC}_{50}$ Tonic \\
\hline & $m V$ & & $n S$ & $m V$ & $\mu M$ \\
\hline $\begin{array}{l}\mathrm{hCa}_{\mathrm{v}} 3.2 \\
\mathrm{hCa}_{\mathrm{v}} 3.2 \mathrm{I} 403 \mathrm{~A} \\
\mathrm{hCa}_{\mathrm{v}} 3.2 \mathrm{~V} 1551 \mathrm{~A} \\
\mathrm{hCa}_{\mathrm{v}} 3.2 \mathrm{~V} 1855 \mathrm{Y}\end{array}$ & $\begin{array}{l}-44.3 \pm 1.4(n=7) \\
-54.0 \pm 1.8(n=11)^{*} \\
-47.0 \pm 1.1(n=13), \mathrm{N} . \mathrm{S} . \\
-29.64 \pm 2.1(n=14)\end{array}$ & $\begin{aligned} 27.3 & \pm 0.7(n=7) \\
20.3 & \pm 1.8(n=11)^{*} \\
23.8 & \pm 1.5(n=13), \mathrm{N} . \mathrm{S} . \\
14.64 & \pm 2.1(n=14)\end{aligned}$ & $\begin{array}{l}-1.9 \pm 0.08(n=7), \text { N.S. } \\
-1.7 \pm 0.09(n=11), \text { N.S. } \\
-1.9 \pm 0.06(n=13), \text { N.S. } \\
-3.9 \pm 0.14(n=14)\end{array}$ & $\begin{array}{l}-64.2 \pm 0.93(n=5), \text { N.S. } \\
-63.8 \pm 0.87(n=6), \text { N.S. } \\
-67.0 \pm 0.98(n=6), \text { N.S. } \\
-58.4 \pm 0.56(n=6)\end{array}$ & $\begin{aligned} 7.0 & \pm 0.51(n=6) \\
20.0 & \pm 1.5(n=6)^{* * *} \\
40.0 & \pm 3.1(n=6)^{* *} \\
1.8 & \pm 0.41(n=6)^{*}\end{aligned}$ \\
\hline
\end{tabular}

N.S., not significant.

$* P<0.05$, relative to wild type.

** $P<0.01$. 


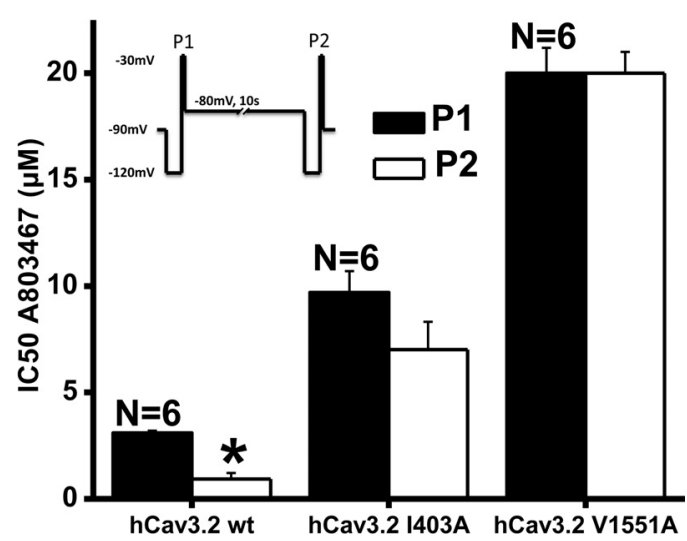

Fig. 6. $\mathrm{IC}_{50}$ values for $\mathrm{A} 803467$ block of slow inactivated $\mathrm{Ca}_{\mathrm{v}} 3.2$ channels using the same protocol as that described in the legend to Fig. 3 except that the holding potential was stepped to $-80 \mathrm{mV}$. Note that the mutant channels do not show an increase in blocking affinity for the slow inactivated state $(*, p<0.05, t$ test $)$. wt, wild-type.

\section{Discussion}

A803467 was originally identified as a potent inhibitor of $\mathrm{hNa}_{\mathrm{v}} 1.8$ channels with a mode of action that seems to involve, at least in part, a stabilization of the slow inactivated state (Jarvis et al., 2007). Furthermore, this compound was shown to reduce neuropathic and inflammatory pain in animal models (McGaraughty et al., 2008). Here, we demonstrate that A803467 also blocks T-type channels with high affinity, with IC50 values that fall into the range of therapeutic concentrations and that block of the $\mathrm{Ca}_{\mathrm{v}} 3.2$ channel subtype seems to stabilize slow inactivation. The similarities between $\mathrm{Na}_{\mathrm{v}} 1.8$ and $\mathrm{Ca}_{\mathrm{v}} 3.2$ channel inhibition by this compound are striking and are underscored by the observation that mutations in $\mathrm{Ca}_{\mathrm{v}} 3.2$ in regions corresponding to the local anesthetic interaction site in sodium channels antagonize A803467 action. Taken together, our findings suggest evolu- tionarily conserved interactions between A803467 and related drugs with $\mathrm{Na}_{\mathrm{v}}$ and $\mathrm{LVA} \mathrm{Ca}_{\mathrm{v}}$ channels.

Both $\mathrm{hNa}_{\mathrm{v}} 1.8$ and T-type $\mathrm{Ca}_{\mathrm{v}} 3.2$ channels are functionally expressed in both nociceptive dorsal root ganglion and lamina I spinal cord neurons (Ikeda et al., 2003; Hildebrand et al., 2010) and are known to regulate their excitability. Hyperfunction of both channel subtypes has been linked to the development of hyperalgesia and allodynia in various animal models of pain (Ikeda et al., 2003; Barton et al., 2005; Cummins et al., 2007). Conversely, knockout or inhibition of Ttype or $\mathrm{Na}_{\mathrm{v}}$ channels mediates analgesia (Bourinet et al., 2005; Choi et al., 2007).

Given the potent blocking effects of A803467 on $\mathrm{Ca}_{\mathrm{v}} 3.2$ channels, it is possible that the previously reported effects of this compound on action potential firing in dorsal root ganglion neurons and the associated analgesia may be, at least in part, mediated by T-type channel inhibition. Given that $\mathrm{Na}_{\mathrm{v}}$ and $\mathrm{Ca}_{\mathrm{v}}$ work together to prolong subthreshold depolarizations within lamina I neurons (Prescott and De Koninck, 2002; Ikeda et al., 2003; Hildebrand et al., 2010), a dual action of A803467 may promote a synergistic inhibition of pain signaling. Slow inactivation is significantly enhanced during prolonged depolarizations or during neuronal burst firing. Promotion of a slow inactivated-like state of both channel subtypes may thus mediate frequency-dependent inhibition of channel activity and therefore reduce overall neuronal excitability. A reduction in neuronal excitability may make compounds such as A803467 ideally suited toward treatment of neuronal hyperexcitability disorders including pain and may perhaps be extended to conditions such as epilepsy. The apparent conservation in the drug receptor site between $\mathrm{Na}_{\mathrm{v}}$ and $\mathrm{Ca}_{\mathrm{v}} 3.2$ channels may provide an opportunity for the synthesis of more potent antagonists acting on both of these channel subtypes.
A

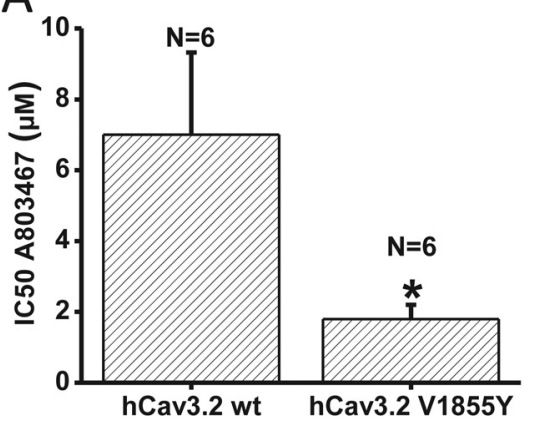

C

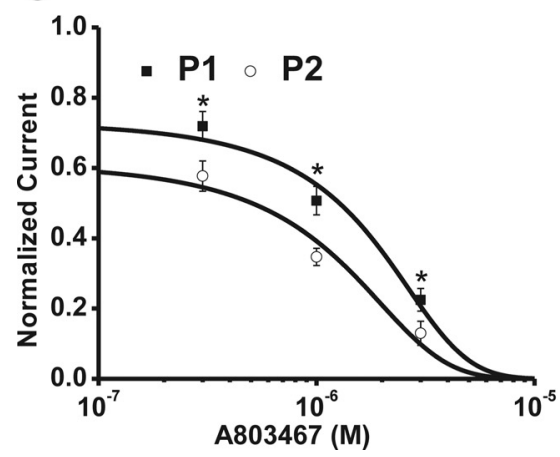

B

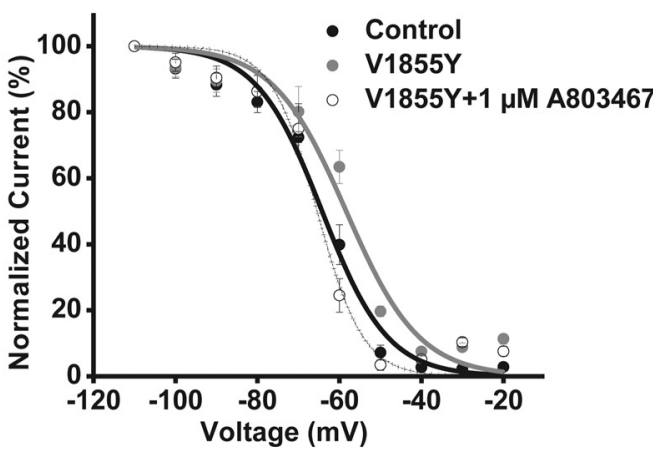

Fig. 7. Effect of a tyrosine substitution in position 1855 of $\mathrm{hCa}_{\mathrm{v}} 3.2$. A, $\mathrm{IC}_{50}$ for tonic $\mathrm{A} 803467$ of wild-type (wt) and mutant V1855Y $(*, p<0.05$, $t$ test). B, steady-state inactivation curves recorded in the presence and the absence of $5 \mu \mathrm{M}$ A803467. Note the hyperpolarizing shift from -58 to -64 $\mathrm{mV}$. For comparison, the inactivation curve of the wild-type (wt) (control) channel is included. C, dose dependence of slow inactivated channel block of mutant $\mathrm{hCa}_{\mathrm{v}} 3.2 \mathrm{~V} 1855 \mathrm{Y}$ expressed as the fractional current at various drug concentrations. Note that the tyrosine substitution produces submicromolar block by this compound. 


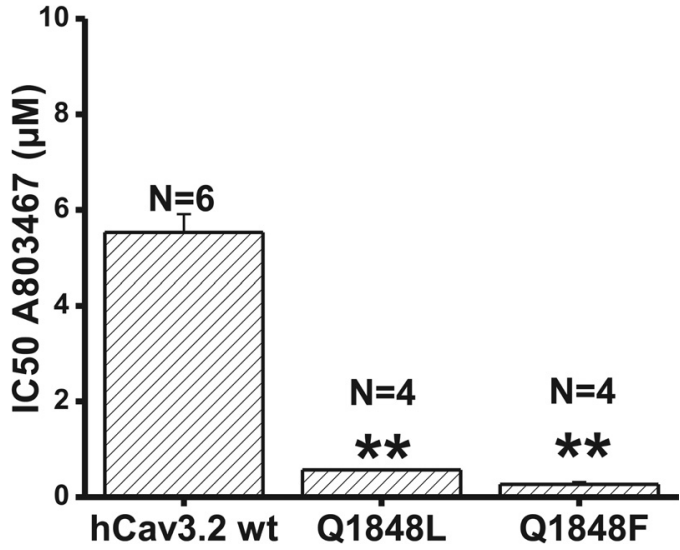

Fig. 8. Summary of $\mathrm{IC}_{50}$ values for tonic A803467 block of wild type (wt) and mutant Q1848L and Q1848F hCa 3.2 channels. Currents were elicited by stepping to a test potential of $-20 \mathrm{mV}$ from a holding potential of $-110 \mathrm{mV}$. Statistical significance relative to control: $* *, p<0.01$. All recordings in this figure were performed in $20 \mathrm{mM}$ barium because of the small current amplitudes of the mutants. $\mathrm{IC}_{50}$ values were obtained by fitting dose-response curves with the Hill equation as described in the legend to Fig. 1. Both substitutions in position 1848 produced submicromolar block by this compound.

\section{Authorship Contributions}

Participated in research design: Bladen and Zamponi.

Conducted experiments: Bladen.

Contributed new reagents or analytic tools: Bladen.

Performed data analysis: Bladen.

Wrote or contributed to the writing of the manuscript: Bladen and Zamponi.

\section{References}

Altier C, Khosravani H, Evans RM, Hameed S, Peloquin JB, Vartian BA, Chen L, Beedle AM, Ferguson SS, Mezghrani A, et al. (2006) ORL1 receptor-mediated internalization of N-type calcium channels. Nat Neurosci 9:31-40.

Altier C and Zamponi GW (2004) Targeting $\mathrm{Ca}^{2+}$ channels to treat pain: T-type versus N-type. Trends Pharmacol Sci 25:465-470.

Barton ME, Eberle EL, and Shannon HE (2005) The antihyperalgesic effects of the T-type calcium channel blockers ethosuximide, trimethadione, and mibefradil. Eur $J$ Pharmacol 521:79-85.

Beedle AM, Hamid J, and Zamponi GW (2002) Inhibition of transiently expressed low- and high-voltage-activated calcium channels by trivalent metal cations. $J$ Membr Biol 187:225-238.

Bender KJ, Uebele VN, Renger JJ, and Trussell LO (2012) Control of firing patterns through modulation of axon initial segment T-type calcium channels. $J$ Physiol 590:109-118.

Blair NT and Bean BP (2002) Roles of tetrodotoxin (TTX)-sensitive $\mathrm{Na}^{+}$current, TTX-resistant $\mathrm{Na}^{+}$current, and $\mathrm{Ca}^{2+}$ current in the action potentials of nociceptive sensory neurons. J Neurosci 22:10277-10290.

Bourinet E, Alloui A, Monteil A, Barrère C, Couette B, Poirot O, Pages A, McRory J, Snutch TP, Eschalier A, et al. (2005) Silencing of the $\mathrm{Ca}_{\mathrm{v}} 3.2$ T-type calcium channel gene in sensory neurons demonstrates its major role in nociception. EMBO J 24:315-324

Cain SM and Snutch TP (2010) Contributions of T-type calcium channel isoforms to neuronal firing. Channels (Austin) 4:475-482.

Catterall WA, Dib-Hajj S, Meisler MH, and Pietrobon D (2008) Inherited neuronal ion channelopathies: new windows on complex neurological diseases. $J$ Neurosci 28:11768-11777.

Catterall WA, Perez-Reyes E, Snutch TP, and Striessnig J (2005) International Union of Pharmacology. XLVIII. Nomenclature and structure-function relationships of voltage-gated calcium channels. Pharmacol Rev 57:411-425.

Choi S, Na HS, Kim J, Lee J, Lee S, Kim D, Park J, Chen CC, Campbell KP, and Shin HS (2007) Attenuated pain responses in mice lacking $\mathrm{Ca}_{\mathrm{V}} 3.2$ T-type channels. Genes Brain Behav 6:425-431.

Cregg R, Momin A, Rugiero F, Wood JN, and Zhao J (2010) Pain channelopathies. J Physiol 588:1897-1904
Cribbs L (2010) T-type calcium channel expression and function in the diseased heart. Channels (Austin) 4:447-452.

Cummins TR, Sheets PL, and Waxman SG (2007) The roles of sodium channels in nociception: implications for mechanisms of pain. Pain 131:243-257.

David LS, Garcia E, Cain SM, Thau E, Tyson JR, and Snutch TP (2010) Splicevariant changes of the $\mathrm{Ca}_{\mathrm{v}} 3.2 \mathrm{~T}$-type calcium channel mediate voltage-dependent facilitation and associate with cardiac hypertrophy and development. Channels (Austin) 4:375-389.

Feng ZP, Doering CJ, Winkfein RJ, Beedle AM, Spafford JD, and Zamponi GW (2003) Determinants of inhibition of transiently expressed voltage-gated calcium channels by $\omega$-conotoxins GVIA and MVIIA. J Biol Chem 278:20171-20178.

Heron SE, Khosravani H, Varela D, Bladen C, Williams TC, Newman MR, Scheffer IE, Berkovic SF, Mulley JC, and Zamponi GW. Scheffer IE, Berkovic SF, Mulley JC, and Zamponi GW (2007) Extended spectrum of idiopathic generalized epilepsies associated with CACNA1H functional variants. Ann Neurol 62:560-568

Hildebrand ME, Smith PL, Bladen C, Eduljee C, Xie JY, Chen L, Fee-Maki M, Doering CJ, Mezeyova J, Zhu Y, et al. (2010) A novel slow-inactivation-specific ion channel modulator attenuates neuropathic pain. Pain 152:833-843.

Hille B (1977) Local anesthetics: hydrophilic and hydrophobic pathways for the drug-receptor reaction. J Gen Physiol 69:497-515.

Ikeda H, Heinke B, Ruscheweyh R, and Sandkühler J (2003) Synaptic plasticity in spinal lamina I projection neurons that mediate hyperalgesia. Science 299:12371240

Isom LL (2001) Sodium channel $\beta$ subunits: anything but auxiliary. Neuroscientist 7:42-54

Jarecki BW, Piekarz AD, Jackson JO 2nd, and Cummins TR (2010) Human voltagegated sodium channel mutations that cause inherited neuronal and muscle channelopathies increase resurgent sodium currents. J Clin Invest 120:369-378.

Jarvis MF, Honore P, Shieh CC, Chapman M, Joshi S, Zhang XF, Kort M, Carroll W, Marron B, Atkinson R, et al. (2007) A-803467, a potent and selective $\mathrm{Na}_{\mathrm{v}} 1.8$ sodium channel blocker, attenuates neuropathic and inflammatory pain in the rat. Proc Natl Acad Sci USA 104:8520-8525.

Khosravani H and Zamponi GW (2006) Voltage-gated calcium channels and idiopathic generalized epilepsies. Physiol Rev 86:941-966.

Lipkind GM and Fozzard HA (2005) Molecular modeling of local anesthetic drug binding by voltage-gated sodium channels. Mol Pharmacol 68:1611-1622.

McGaraughty S, Chu KL, Scanio MJ, Kort ME, Faltynek CR, and Jarvis MF. Scanio MJC, Kort ME, and Jarvis MF (2008) A selective $\mathrm{Na}_{\mathrm{v}} 1.8$ sodium channel blocker, A-803467 [5-(4-chlorophenyl- $N$-(3,5-dimethoxyphenyl)furan-2-carboxamide], attenuates spinal neuronal activity in neuropathic rats. $J$ Pharmacol Exp Ther 324:1204-1211.

Park J and Luo ZD (2010) Calcium channel functions in pain processing. Channels (Austin) 4:510-517.

Perez-Reyes E (2003) Molecular physiology of low-voltage-activated T-type calcium channels. Physiol Rev 83:117-161.

Prescott SA and De Koninck Y (2002) Four cell types with distinctive membrane properties and morphologies in lamina I of the spinal dorsal horn of the adult rat. J Physiol 539:817-836.

Ragsdale DS, McPhee JC, Scheuer T, and Catterall WA (1994) Molecular determinants of state dependent block of Na channels by local anesthetics. Science $\mathbf{2 6 5}$ 1724-7228.

Sheets PL, Heers C, Stoehr T, and Cummins TR (2008) Differential block of sensory neuronal voltage-gated sodium channels by lacosamide [( $2 R)-2$-(acetylamino)-Nbenzyl-3-methoxypropanamide], lidocaine, and carbamazepine. J Pharmacol Exp Ther 326:89-99.

Wang W, Gu J, Li YQ, and Tao YX (2011) Are voltage-gated sodium channels on the dorsal root ganglion involved in the development of neuropathic pain? Mol Pain 7:16

Waxman SG, Cummins TR, Dib-Hajj S, Fjell J, and Black JA (1999) Sodium channels, excitability of primary sensory neurons, and the molecular basis of pain. Muscle Nerve 22:1177-1187.

Yarov-Yarovoy V, Brown J, Sharp EM, Clare JJ, Scheuer T, and Catterall WA (2001) Molecular determinants of voltage-dependent gating and binding of pore-blocking drugs in transmembrane segment IIIS6 of the $\mathrm{Na}^{+}$channel $\alpha$ subunit. $J$ Biol Chem 276:20-27.

Yarov-Yarovoy V, McPhee JC, Idsvoog D, Pate C, Scheuer T, and Catterall WA. McPhee JC, Idsvoog D, Pate C, Scheuer T, and Catterall WA (2002) Role of amino acid residues in transmembrane segments IS6 and IIS6 of the $\mathrm{Na}^{+}$channel a subunit in voltage-dependent gating and drug block. J Biol Chem 277:3539335401

Yu FH and Catterall WA (2004) The VGL-chanome: a protein superfamily specialized for electrical signaling and ionic homeostasis. Sci STKE 253:re15.

Address correspondence to: Dr. Gerald W. Zamponi, Department of Physiology and Pharmacology, University of Calgary, 3330 Hospital Dr. NW, Calgary, AB, T2N 4N1, Canada. E-mail: zamponi@ucalgary.ca 